\title{
Experiences During Synthesis of a Dinucleating Spacer Incorporating 2-Chloropyridine Units Through Sandmayer Reaction
}

\author{
SATYENDRA N. SHUKLA ${ }^{\mathrm{a}^{*}}$, PRATIKSHA GAUR ${ }^{\mathrm{a}}$, \\ RIPUL MEHROTRA ${ }^{\mathrm{b}}$, and RADHEY S. SRIVASTAVA ${ }^{\mathrm{c}}$ \\ ${ }^{a}$ Coordination Chemistry Research Lab \\ Department of Chemistry \\ Govt. Model Science College Jabalpur (MP) 482001, India \\ ${ }^{\mathrm{b}}$ Assistant Professor of Chemistry \\ Department of Engineering Chemistry \\ ITM University \\ Gwalior,MP,INDIA \\ ${ }^{c}$ University of Louisiana at Lafayette, LA, 70504, USA \\ sns1963_1@rediffmail.com
}

Received 17 March 2011; Revised 28 May 2011; Accepted 21 December 2011

\begin{abstract}
A bimetallic cuprous complex was accidentally reported, during synthesis of a dinucleating spacer incorporating two 2-chloropyridine units through Sandmayer reaction. The product was characterized by elemental analysis, FAB-Mass, FT-IR, UV, magnetic susceptibility and ${ }^{1} \mathrm{H}-\mathrm{NMR}$ spectroscopic method. A possible mechanism is also proposed.
\end{abstract}

Keywords: $\mathrm{Cu}(\mathrm{I}) \mathrm{Cu}(\mathrm{II})$ complex, Sandmayer reaction, Cuprous chloride, Spacer.

\section{Introduction}

Synthesis of bidentate heterocyclic ligands containing pyridine nucleus with potential coordinating ability has drawn a lot of attention because of their fungicidal, antimicrobial and antibacterial properties ${ }^{1}$. In order to synthesize a novel spacer containing chloro group at ortho position to pyridine nitrogen, we have synthesized tetrazonium salt by diazotization of 5,5'-methylenebis(2-aminopyridine). Thereafter Sandmayer reaction was applied to introduce chloro group, by evolving $\mathrm{N}_{2}$, in corresponding diazonium salt solution. Reaction is catalyzed with cuprous chloride salt ${ }^{2}$. Surprising results were obtained, when reaction is applied to tetrazonium salt solution of 5,5'-methylenebis(2-aminopyridine) ${ }^{3}$. It was observed that catalyst lost its identity by participating in reaction. Thus this communication presents our experience, which we observed during synthesis of a dinucleating spacer incorporating two 2-chloropyridine units. 


\section{Experimental}

2-Aminopyridine (Himedia), formaldehyde (E. Merck), sodium nitrite (Himedia), cuprous chloride (E. Merck) was used as received. Hydrochloric acid, ethanol and routine solvent were used without further purification for synthesis purpose. FT-IR spectra were recorded in $\mathrm{KBr}$ pellets on shimadzu-8400 PC, FT-IR spectrophotometer. ${ }^{1} \mathrm{H}-\mathrm{NMR}$ spectra were recorded in $\mathrm{D}_{2} \mathrm{O}$ on a Bruker DRX-300 NMR spectrometer. Elemental analyses $(\mathrm{CHN})$ were performed on Elementra Vario EL III, Elemental analyzer. Electronic absorption spectra were recorded with shimadzu-1700, UV spectrophotometer equipped with a PC. Conductivity measurements were carried out at $25^{\circ} \mathrm{C}$ on an EI-181 conductivity bridge with a dipping type cell. FAB-Mass spectra were recorded on Jeol SX-102 Mass spectrometer using NBA as matrix. The whole experimental procedure was completed in three steps.

In first step, 5,5'-methylenebis(2-aminopyridine) was prepared according to method of Pradeep et al. ${ }^{3}$

To solution of 2-aminopyridine, $(0.9412 \mathrm{~g}, 0.01 \mathrm{~mol})$ in water $(25 \mathrm{~mL})$, formaldehyde, $(0.14 \mathrm{~mL}$, $0.005 \mathrm{~mol}$ ) was added slowly with constant stirring for $2 \mathrm{~h}$. A white cream solid was precipitated, which was filtered, washed with water, dried in vacuum and recrystallized from ethanol. $(0.8642$ g, 86.3\%). $\mathrm{Mp}=92{ }^{\circ} \mathrm{C}$; Found: $\mathrm{C}, 65.93 ; \mathrm{H}, 6.08 ; \mathrm{N}, 27.92 ; \mathrm{C}_{11} \mathrm{H}_{12} \mathrm{~N}_{4}(\mathrm{M} \tau=200)$. Requires: $\mathrm{C}$, 65.99; H, 6.04; N, 27.98. $v_{\max }(\mathrm{KBr}) \mathrm{cm}^{-1}: 3487(\mathrm{~s}), 3077(\mathrm{~s}), 2860(\mathrm{~s}), 2841(\mathrm{~s}), 1609(\mathrm{~s}), 1595(\mathrm{~s})$, 1516(s), 1430(s), 737(s). $\delta_{\mathrm{H}}: 7.49-6.52(\mathrm{~m}, 6 \mathrm{H}) ; 5.44(\mathrm{brs}, 4 \mathrm{H}) ; 2.82(\mathrm{~s}, 2 \mathrm{H})$.

In second step, recrystallized 5,5'-methylenebis(2-aminopyridine), $(0.130 \mathrm{~g}, 0.650 \mathrm{mmol})$, was dissolved in concentrated hydrochloric acid $(0.05 \mathrm{~mL}, 1.3 \mathrm{mmol})$ and water $(3 \mathrm{~mL})$. After cooling to $\sim 5^{\circ} \mathrm{C}$ temperature, solution of sodium nitrite, $(0.0897 \mathrm{~g}, 1.3 \mathrm{mmol})$ in water $(5 \mathrm{~mL})$ was added drop wise. External cooling has been done to maintain the temperature.

In third step, cuprous chloride $(0.1286 \mathrm{~g}, 1.3 \mathrm{mmol})$, was dissolved in concentrated hydrochloric acid and water (1:1), in a round bottom flask and heated on water bath. Removed water bath and support the flask on stand, now tetrazonium solution obtained in step-2 was added drop wise with shaking. Color of reaction solution becomes light green. The light green solution was evaporated under vacuum, washed with diethyl ether. In the solid-state Color of the product becomes brown. $(0.6284 \mathrm{~g}, 83.3 \%) . \mathrm{M}_{\mathrm{D}}=153{ }^{\circ} \mathrm{C}$; Found: $\mathrm{C}$, 22.73; H, 2.80; N, 4.82; $\mathrm{C}_{11} \mathrm{H}_{16} \mathrm{~N}_{2} \mathrm{O}_{4} \mathrm{Cl}_{6} \mathrm{Cu}_{2}(\mathrm{M} \tau=580)$. Requires: $\mathrm{C}, 22.78 ; \mathrm{H}, 2.78 ; \mathrm{N}, 4.83$. $v_{\max }(\mathrm{KBr}) \mathrm{cm}^{-1}: 3169(\mathrm{~s}), 3000(\mathrm{~s}), 2873(\mathrm{~s}), 2847(\mathrm{~s}), 1640(\mathrm{~s}), 1622(\mathrm{~s}), 1540(\mathrm{~m}), 1462(\mathrm{~s})$, 1104(s), 851(s), 765(s), 518(m), 443(w), 312(w). $\lambda_{\max }, \mathrm{nm}\left(\varepsilon\right.$ in $\left.\mathrm{M}^{-1} \mathrm{~cm}^{-1}\right): 297(1082)$, 230(980). $\mu \mathrm{eff}=1.81 \mathrm{BM}, \Delta \mathrm{m}$ at $25^{\circ} \mathrm{C}\left(\Omega^{-1}\right.$ in $\left.\mathrm{M}^{-1} \mathrm{~cm}^{-1}\right): 123 . \delta_{\mathrm{H}}: 7.76-6.63(\mathrm{~m}, 6 \mathrm{H})$; 4.82(s,8H); 2.85(s,2H). $m / z(\mathrm{FAB}) 581(\mathrm{M}+\mathrm{H})^{+}$.

\section{Results and Discussion}

Empirical formula of the resultant product was in conformity with elemental analysis. Molecular weight was also confirmed with FAB-Mass spectrometric study, where $(\mathrm{M}+\mathrm{H})^{+}$ peak was observed (Figure 1). The high molecular conductance was recorded in water, indicated ionic nature of product ${ }^{4}$.

In FT-IR spectra, three new bands appeared in region $518-312 \mathrm{~cm}^{-1}$, are due to $\mathrm{Cu}-\mathrm{O}$, $\mathrm{Cu}-\mathrm{N}$ and $\mathrm{Cu}-\mathrm{Cl}$ bands, respectively, ${ }^{5,6}$. Two sharp peaks observed at 851 and $765 \mathrm{~cm}^{-1}$ are due to rocking mode of coordinated water molecule ${ }^{7}$. A new sharp band appeared at $1104 \mathrm{~cm}^{-1}$, assigned for $v(\mathrm{C}-\mathrm{Cl})$ stretching vibration. Two bands observed at 2873 and $2847 \mathrm{~cm}^{-1}$, assigned for $-\mathrm{CH}_{2}$ stretching mode ${ }^{8}$. Four sharp signals observed in between 1609-1430 $\mathrm{cm}^{-1}$, assigned for cyclic $\mathrm{C}=\mathrm{C}$ and $\mathrm{C}=\mathrm{N}$ in ligand. Product displays positive shifts by $\sim 30 \mathrm{~cm}^{-1}$ and also found less intense than ligand spectra, indicating that both metal centers are in 
symmetrically coordination with pyridine nitrogen ${ }^{9}$. In UV region, $\mathrm{L} \rightarrow \mathrm{M}$ charge transfer band (MLCT) appeared at 297 and $230 \mathrm{~nm}$, also support our view ${ }^{10}$.

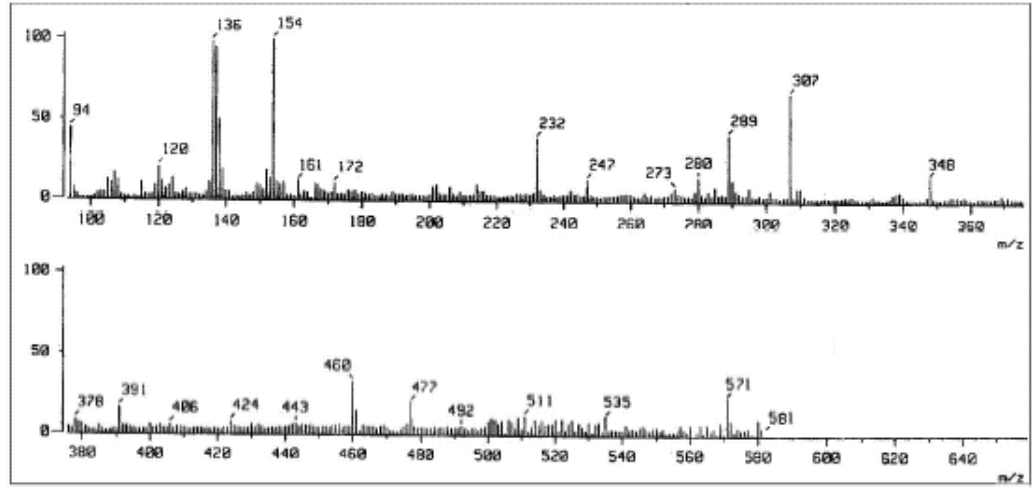

Figure 1. FAB-Mass spectra of cuprous product.

Oxidation state of copper in complex depends on the kind of reaction and working conditions. In neutral or alkaline solutions, $\mathrm{Cu}$ (II) complexes exist; while in warm acidic solution copper exist as cuprous ion. Thus acidity of solution is an important factor to catalyze redox reaction ${ }^{10}$. The absence of band around $360 \mathrm{~nm}$, which is characteristic for dimeric $\mathrm{Cu}(\mathrm{II})$ complex, also supports the presence of $\mathrm{Cu}(\mathrm{I})$ in product $^{11}$.

In the ${ }^{1} \mathrm{H}-\mathrm{NMR}$ spectra of the product (Figure 2), singlet at $\delta 2.85 \mathrm{ppm}$ was assigned for two methylenic protons and multiplet in range $\delta 7.76-6.63 \mathrm{ppm}$, was assigned for six hetero aromatic protons. However the singlet observed at $\delta 4.82 \mathrm{ppm}$; indicating same environment of protons for all the coordinated water molecule ${ }^{8}$.

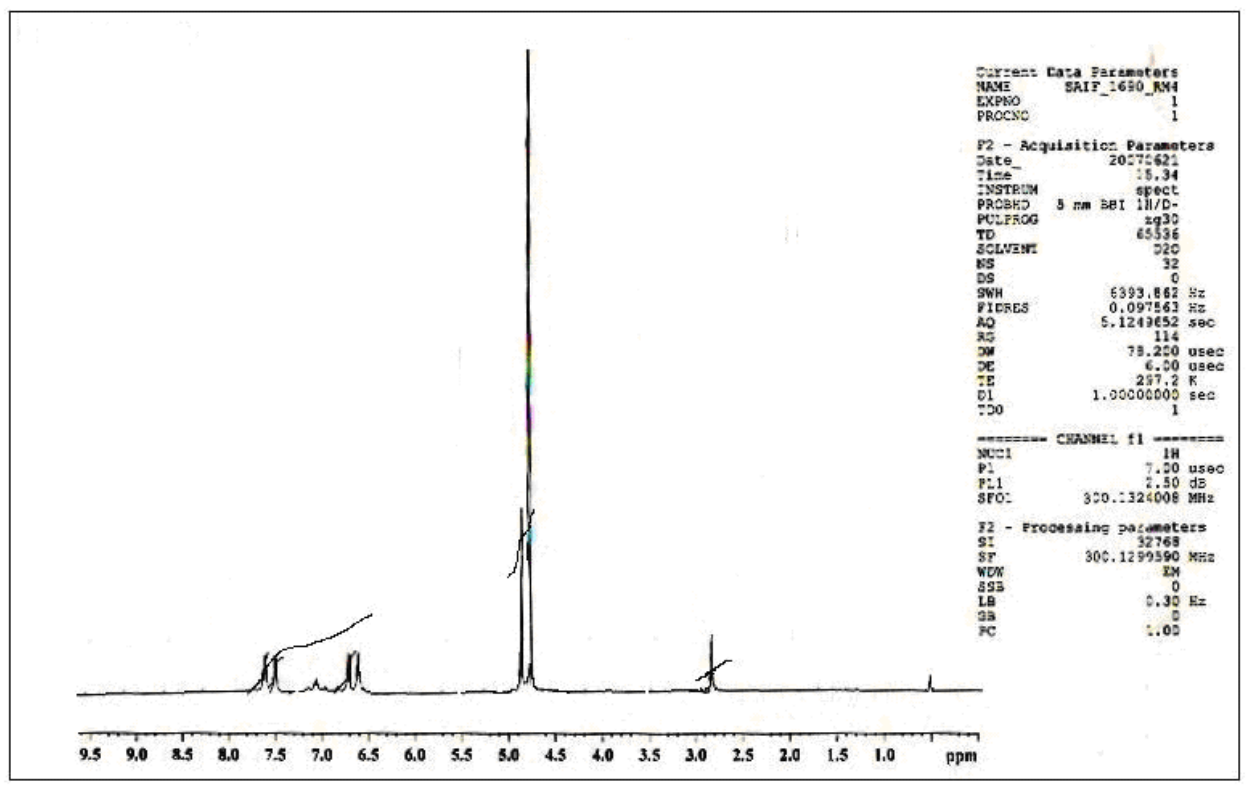

Figure 2. ${ }^{1} \mathrm{H}-\mathrm{NMR}$ spectra of cuprous product. 
It was interesting to see that Color of product becomes brown in solid state, probably due to inter conversion of $\mathrm{Cu}(\mathrm{I})$ to $\mathrm{Cu}(\mathrm{II})$, which was also supported by magnetic susceptibility measurements. We suggest that in solution copper exist in +1 oxidation state with trigonal planar geometry ${ }^{10}$ and in solid state copper exist in +2 oxidation state with square planar geometry. Its inter conversion between these two structure may be represented as (Figure 3). Primary valency was satisfied through $\mathrm{Cl}^{-}$, also verified qualitatively by silver nitrate test.

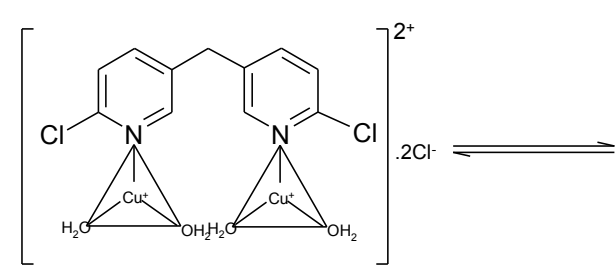

Trigonal planar (in liquid)

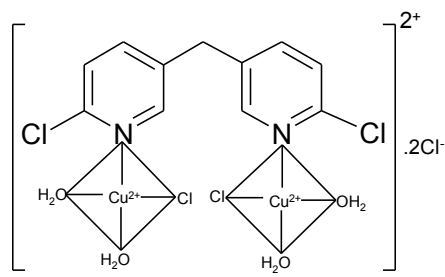

Square planar (in solid)

Figure 3. Inter conversion of $\mathrm{Cu}(\mathrm{I})$ and $\mathrm{Cu}(\mathrm{II})$.

\section{Conclusion}

Thus on the basis of above evidences it can be concluded that in this case during Sandmayer reaction, $\mathrm{Cu}^{+}$ion (of catalyst $\mathrm{CuCl}$ ), was regenerated at the end of reaction and probably trapped by hetero aromatic Lewis base moiety. Therefore, catalyst lost its identity and we fails to achieve the synthesis of desired spacer. Thus, the more probable structure and mechanism ${ }^{12}$, of product was suggested. (Figure 4)

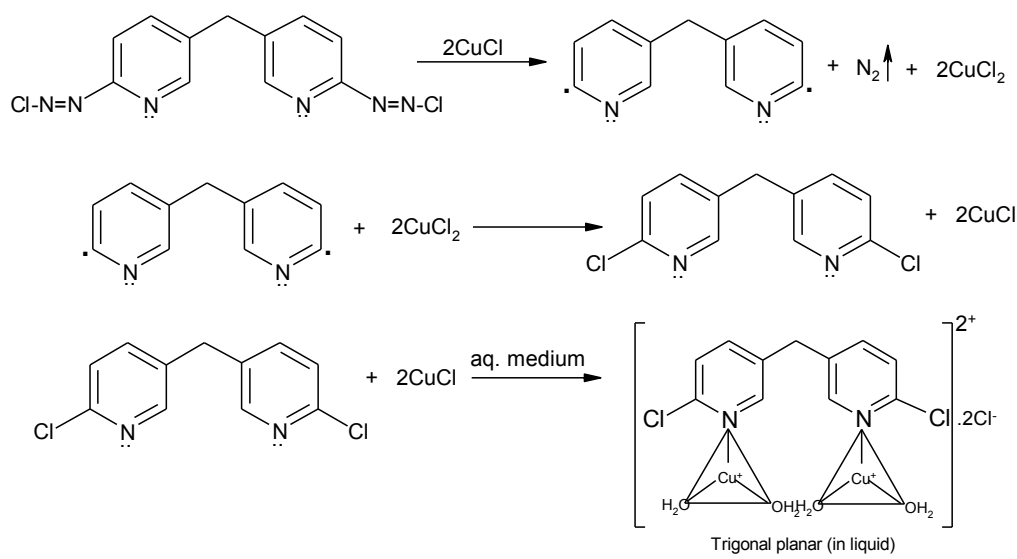

Figure 4. Probable mechanism.

\section{Acknowledgment}

We are thankful to Principal and Head (Chemistry) Govt. Science College, Jabalpur for providing laboratory facilities; SAIF, CDRI, Lucknow for ${ }^{1} \mathrm{H}-\mathrm{NMR}$, FAB-Mass and CHN analysis; Prof. K. K. Verma, (Chemistry) RDVV, Jabalpur for his kind help rendered in recording FT-IR spectra and to Prof. M. P. Sahastrabudhey (Retd. Professor Chemistry) Govt. Model Science College, Jabalpur for the helpful discussion. 


\section{References}

1. Wei Q, Ding C, Zhang S S and Liu N, Asian J Chem., 2006, 18(3), 1895.

2. Mann F G and Saunders B C, Practical Organic Chemistry; Orient Longman Ltd. India: 1999, 189.

3. Pradeep T, Karunakar P, Jadhav W N, Pawar R P and Bhusare S R, Int J Chem Sci., 2003, 1(13), 277.

4. Shukla S N, Gaur P, Mehrotra R, Prasad M, Kaur H, Prasad M and Srivastava R S, $J$ Coord Chem., 2009, 62(15), 2556.

5. Sharma R, Bansal K A and Nagar M, Ind J Chem., 2005, 44A, 2256.

6. Thomas M, Nair M K M and Radhakrishan R K, Synth React Inorg Met-org Chem., 1995, 25, 471.

7. Singh B, Srivastava A K and Singh P K, Ind J Chem., 1997, 36A, 72.

8. Silverstein R M, Bassler G C and Morrill T C, Spectrometric Identification of Organic Compounds; John Wiley and sons inc., New York: 1991, 130, 262.

9. Srivastava R S, Fronczek F R and Romero L M, Inorg Chimi Acta, 2004, 357, 2410.

10. Tascioglu S, Ind J Chem., 2007, 46A, 80.

11. Tsuchida R, Yamada S, Nature (London) 1955, 176, 1171.

12. March J, Advanced Organic Chemistry; Fourth Edn., John Wiley and sons, Singapore: 1992, 723. 


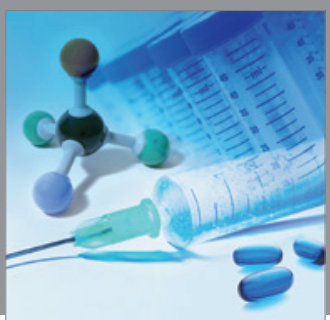

International Journal of

Medicinal Chemistry

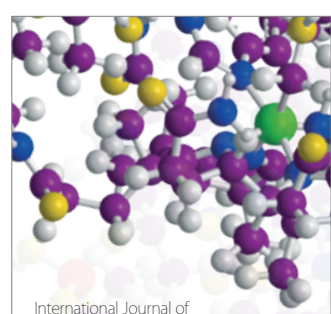

Carbohydrate Chemistry

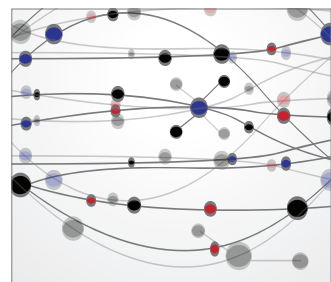

The Scientific World Journal
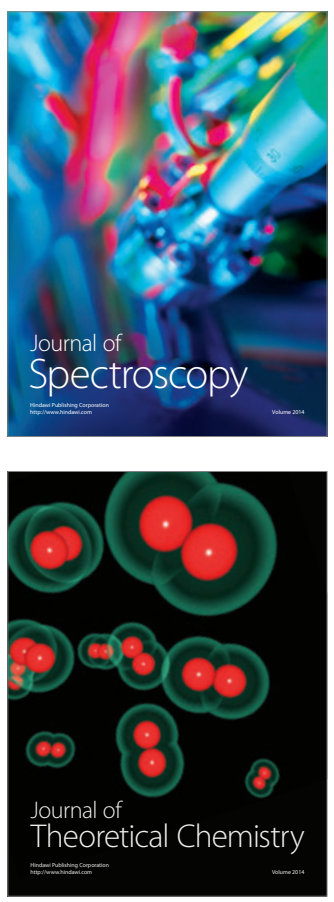
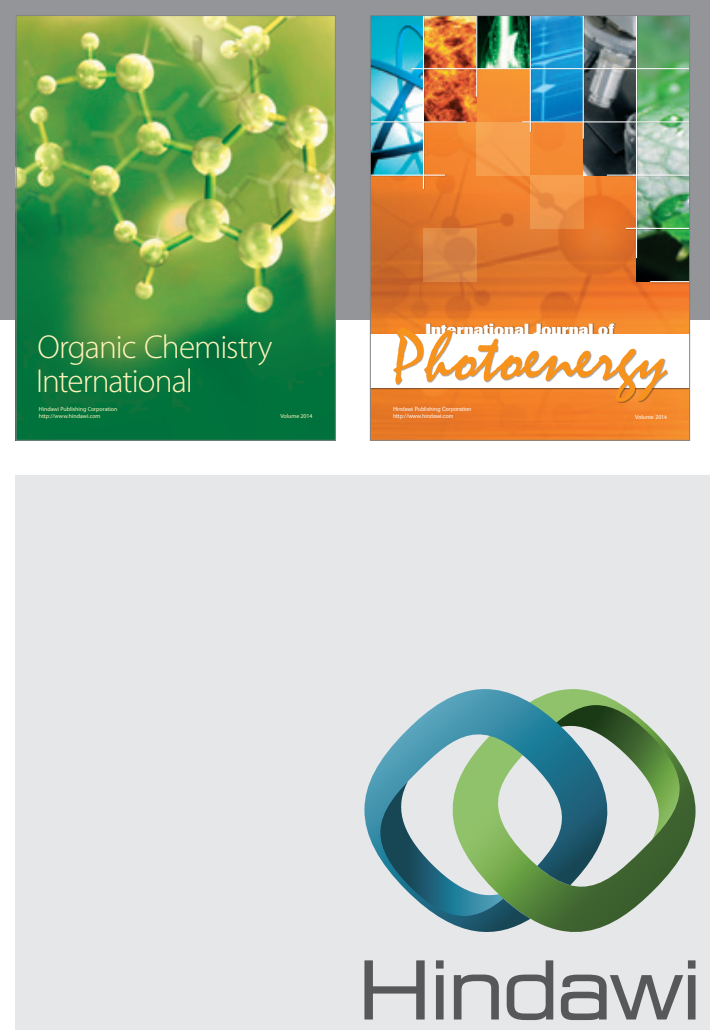

Submit your manuscripts at

http://www.hindawi.com
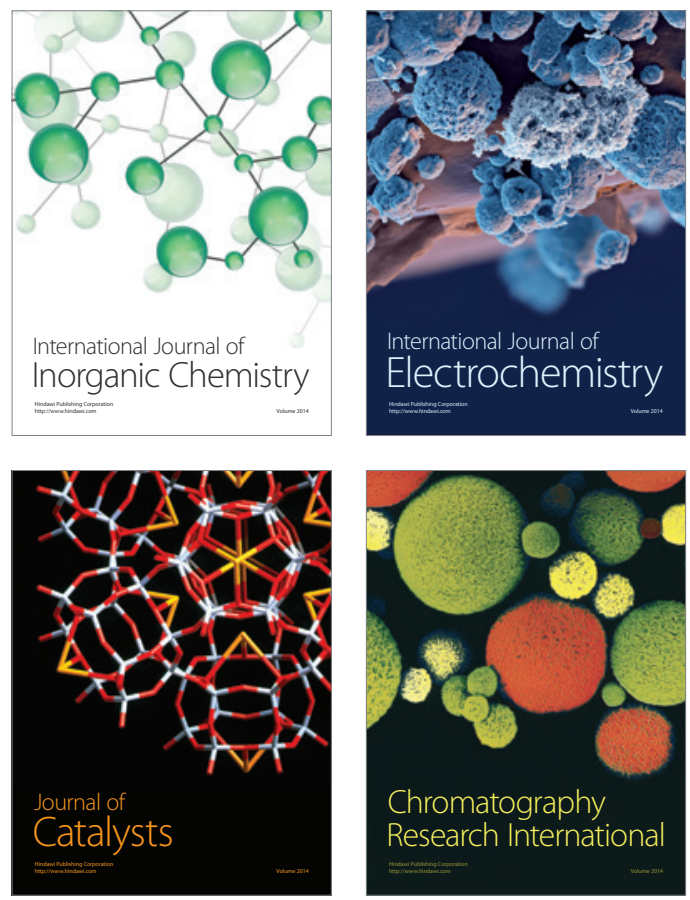
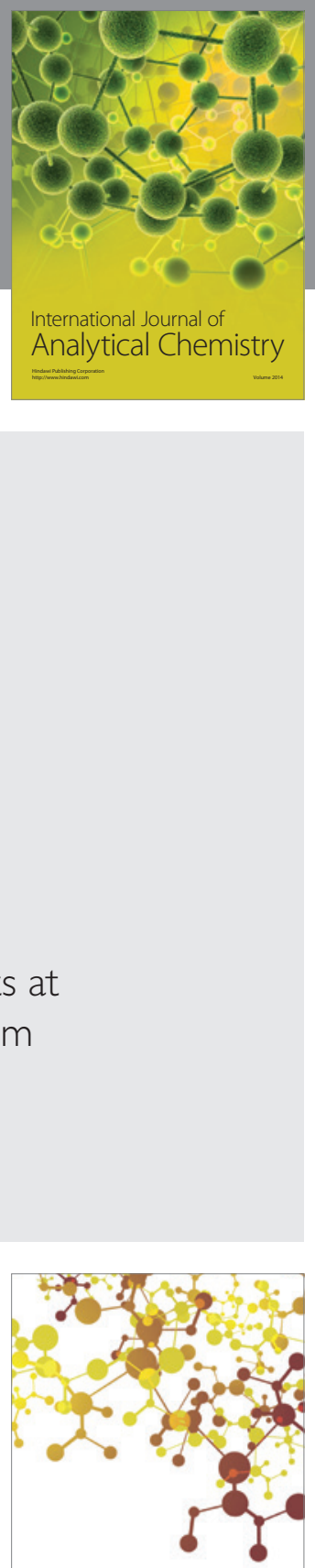

Journal of

Applied Chemistry
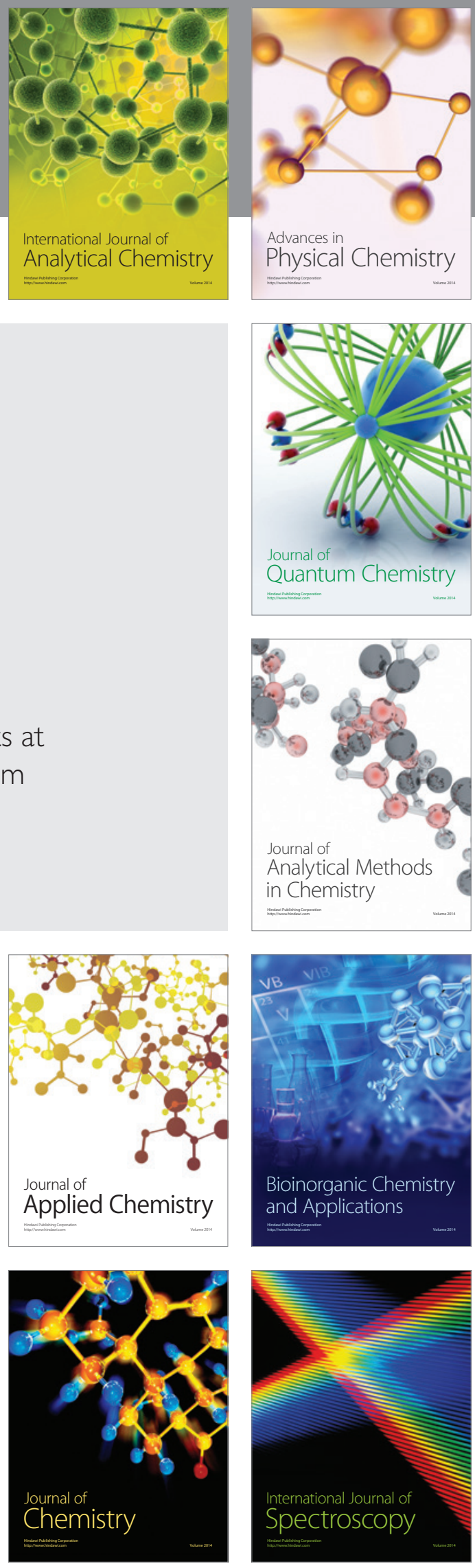